\title{
Accelerating Improvement in Children's Healthcare Through Quality Improvement Collaboratives: a Synthesis of Recent Efforts
}

Michael Terao, MD, FAAP ${ }^{1}$

James M. Hoffman, PharmD, $M S^{2}$

Richard J. Brilli, MD, FAAP, MCCM ${ }^{3}$

Amanda Finch, $B S, P M P,{ }^{4}$

Kathleen E. Walsh, MD, MS

Maitreya Coffey, MD, FAAP, $\operatorname{FRCP}(C)^{6,7 \text {,* }}$

\section{Address}

${ }^{1}$ Department of Oncology, St. Jude Children's Research Hospital, Memphis, TN, USA

${ }^{2}$ Office of Quality and Patient Care and Department of Pharmaceutical Sciences, St. Jude Children's Research Hospital, Memphis, TN, USA

${ }^{3}$ Nationwide Children's Hospital; Pediatrics, Ohio State University College of Medicine, Columbus, OH, USA

${ }^{4}$ Children's Hospitals' Solutions for Patient Safety and Cincinnati Children's, Cincinnati, $\mathrm{OH}$, USA

${ }^{5}$ James M Anderson Center for Health Systems Excellence, Cincinnati Children's, Cincinnati, $\mathrm{OH}$, USA

${ }^{*}{ }^{*}$ Children's Hospitals' Solutions for Patient Safety, Cincinnati, OH, USA

Email: trey.coffey@sickkids.ca

${ }^{7}$ The Hospital for Sick Children, Toronto, Ontario, Canada

Published online: 4 May 2019

(C) Springer Nature Switzerland AG 2019

This article is part of the Topical Collection on Patient Safety

Keywords Quality improvement collaborative · Pediatrics · Patient safety · Quality improvement

Abbreviations AAP American Academy of Pediatrics - ACR American College of Rheumatology • Bright STAR Blood Culture Improvement Guidelines and Diagnostic Stewardship for Antibiotic Reduction in Critically Ill Children • CCBDN Childhood Cancer \& Blood Disorders Network - CFF Cystic Fibrosis Foundation • CHA Children's Hospital Association - IPSO Improving Pediatric Sepsis Outcomes - NAPRTCS North American Pediatric Renal Trials and Collaborative Studies - OCHA Ohio Children's Hospital Association - OCHSPS Ohio Children's Hospitals' Solutions for Patient Safety - QIC Quality improvement collaborative - SCDTDP Sickle Cell Disease Treatment Demonstration Program - SCOPE Standardizing Care to Improve Outcomes in Pediatric End Stage Renal Disease - SPS Children's Hospitals' Solutions for Patient Safety · VIP Value in Inpatient Pediatrics 


\begin{abstract}
Purpose of review Quality improvement collaboratives can accelerate quality improvement and patient safety efforts. We reviewed major pediatric quality improvement collaboratives that have published results in the past 5 years and discussed common success factors and barriers encountered by these collaboratives.

Recent findings Many pediatric quality improvement collaboratives are active in neonatal, cystic fibrosis, congenital heart disease, hematology/oncology, chronic kidney disease, rheumatology, critical care, and general pediatric care.

Summary Factors important to the success of these pediatric quality improvement collaboratives include data sharing and communication, trust among institutions, financial support, support from national organizations, use of a theoretical framework to guide collaboration, patient and family involvement, and incentives for participation at both the individual and institutional levels. Common barriers encountered by these collaboratives include insufficient funding or resources, legal concerns, difficulty coming to consensus on best practices and outcome measures, and overcoming cultural barriers to change. Learning from the successes and challenges encountered by these collaboratives will enable the pediatric healthcare quality improvement community to continue to evolve this approach to maximize benefits to children.
\end{abstract}

\title{
Introduction
}

Despite significant effort over the last two decades, preventable harm and gaps in quality of care continue to affect children receiving healthcare [1-3]. Implementing best practices to improve the quality of healthcare can be hampered by lack of awareness, familiarity, or agreement; lack of skills or motivation; and external barriers such as insufficient time [4]. Quality improvement collaboratives (QICs) can help to overcome many of these barriers. Involving multiple institutions in a shared improvement effort spreads knowledge and skill, builds social pressure to engage clinicians, and pools resources to overcome barriers to improving the quality of healthcare.

A systematic review of 220 QICs found that $83 \%$ of the examined studies reported improvement in one or

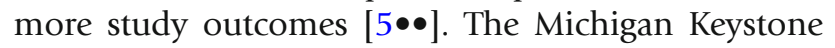
intensive care unit (ICU) project, a well-known QIC, reduced the rate of catheter-related bloodstream infections in ICUs through five relatively simple and low-cost interventions that resulted in preventing approximately
29.9 catheter-related bloodstream infections and saving 3.4 to 7.2 lives per year per hospital $[6,7]$.

In this review, we focus on the most significant pediatric QIC publications from the last 5 years, including a narrative that provides the history of these QICs (Table 1). Using the definition by Wells et al.: "A QIC is an organised, multifaceted approach that includes teams from multiple healthcare sites coming together to learn, apply and share improvement methods, ideas and data on service performance for a given healthcare topic," we identified published pediatric QICs that meet this definition by conducting a comprehensive review of literature complemented by the authors' knowledge $[5 \bullet \bullet$. QICs were included on the basis of size, scope, and impact on care. The review also briefly examines other noteworthy groups, including those that meet the QIC definition but have not yet published their results. Finally, success factors and barriers described in the literature are summarized. 


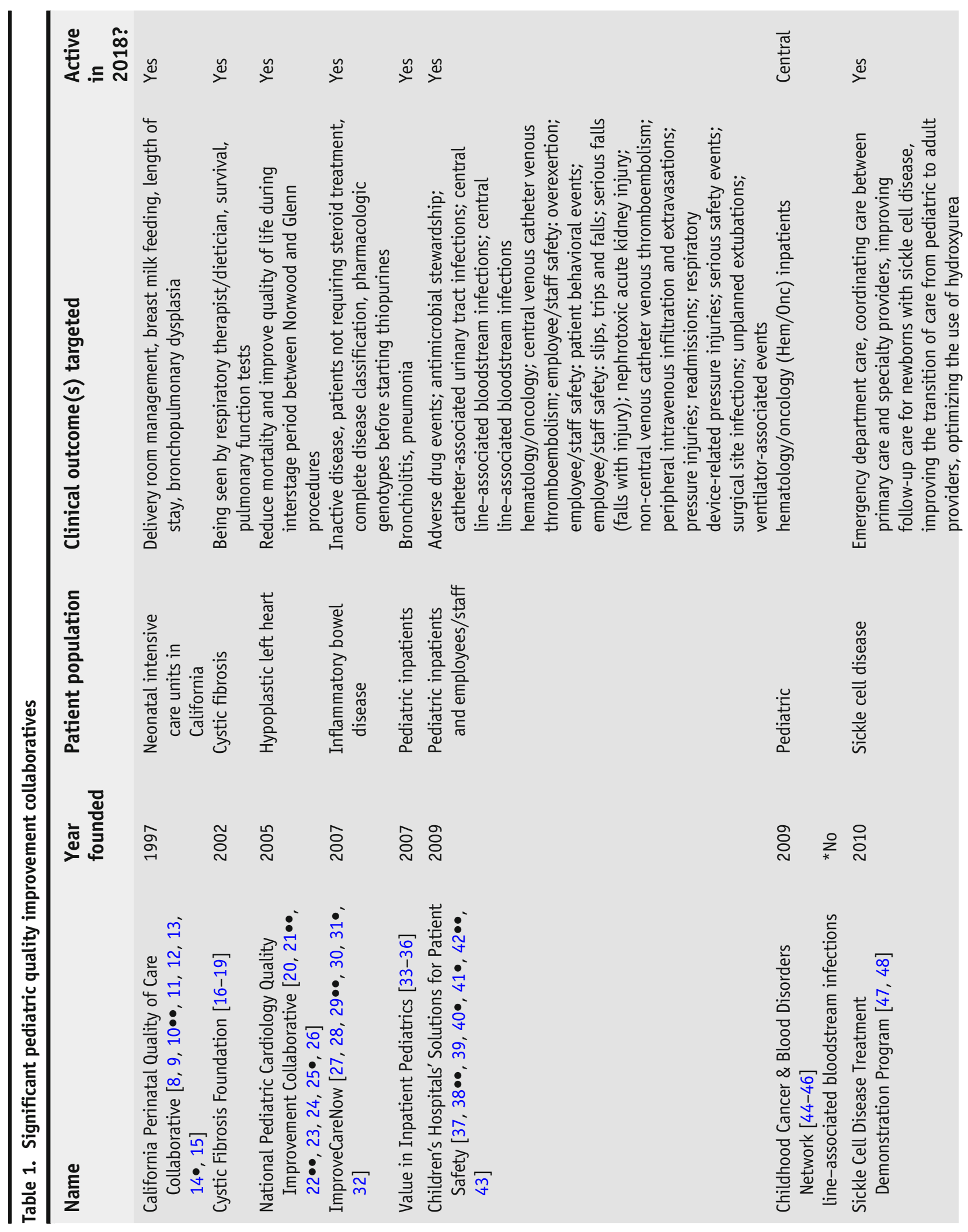




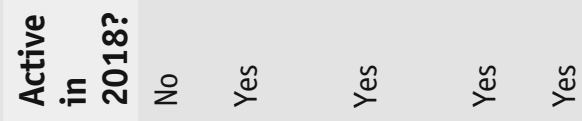
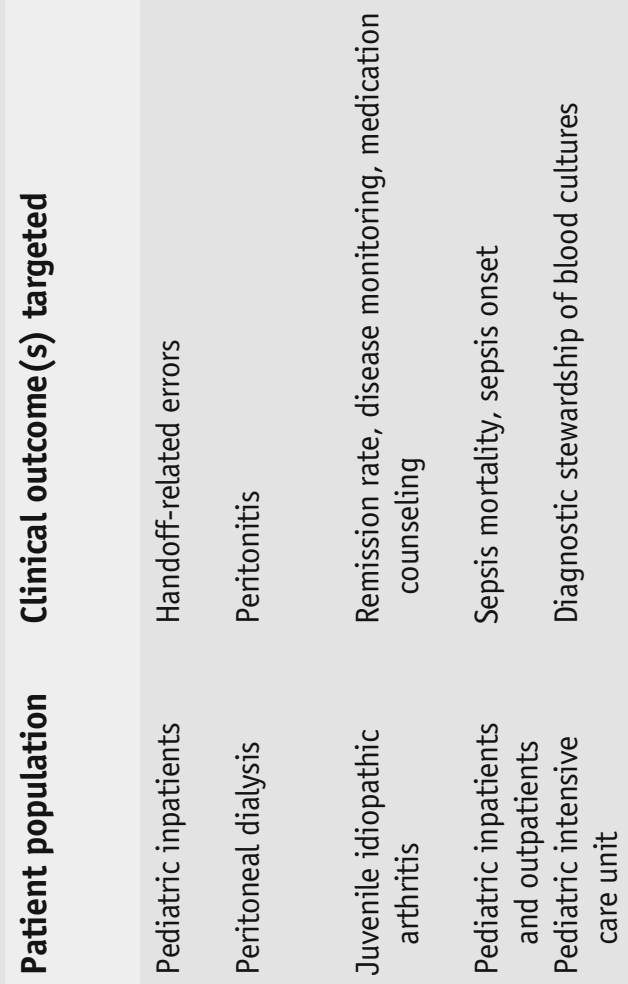

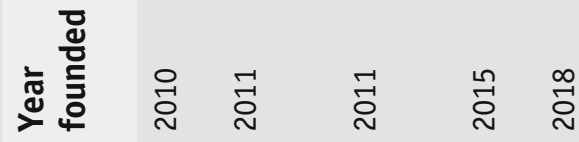

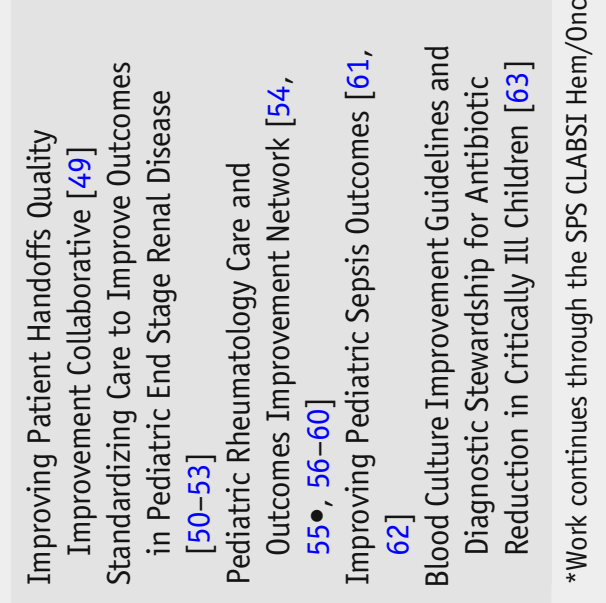




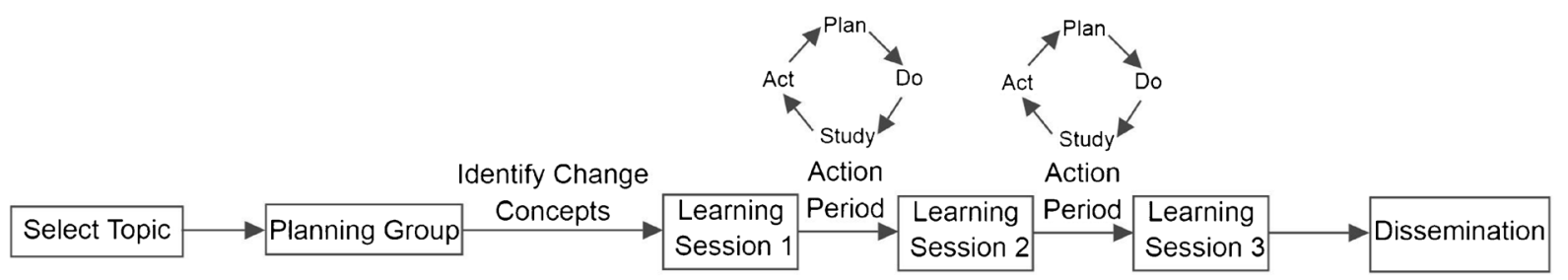

Fig. 1. The Breakthrough Series collaborative model adapted from Kilo 1998 [64].

\section{A framework for collaborative quality improvement}

\section{Breakthrough Series collaborative model}

A framework extensively used by QICs is the Breakthrough Series collaborative model from the Institute for Healthcare Improvement $[5 \bullet \bullet, 64]$. This model targets a specific clinical topic for improvement and then uses learning sessions and Plan-Do-Study-Act (PDSA) cycles to accelerate improvement by drawing upon the shared successes and failures of each member (Fig. 1) [64]. Learning sessions function as important waypoints to determine the changes needed to improve in the clinical area (learning session 1), assess the progress made and share findings from involved organizations (learning session 2), and summarize what has been learned from this improvement process (learning session 3 ). During action periods, PDSA cycles occur and organizations share their knowledge and experiences through site visits, conference calls, or other forms of communication. Many QICs also share features of the Learning Healthcare System model [65].

\section{Pediatric quality improvement collaboratives}

\section{CPQCC}

Founded in 1997 by the California Association of Neonatologists with foundation and state funds, the California Perinatal Quality of Care Collaborative (CPQCC) includes 128 neonatal intensive care units (NICUs) caring for more than $90 \%$ of NICU patients in California $[8,9]$. The CPQCC uses the Breakthrough Series collaborative model $[10 \bullet \bullet, 64]$. The CPQCC has implemented a delivery room checklist that reached $80 \%$ compliance [8]. This collaborative decreased the rate of bronchopulmonary dysplasia (odds ratio 0.8 ), decreased hypothermia and intubation in the delivery room, decreased postmenstrual age at discharge from 37.8 to 37.5 weeks $(P=0.02)$, decreased length of stay and treatment for patients with neonatal abstinence syndrome, and increased breast milk feeding rates from 54.6 to $61.7 \%$ with necrotizing enterocolitis rates

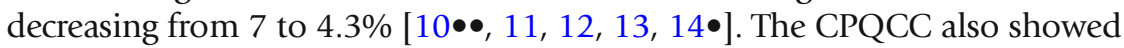
that NICUs participating in QICs had greater improvement than did NICUs working alone $[10 \bullet \bullet, 12,13]$. 
Aided by the Cystic Fibrosis Foundation (CFF) patient registry created in 1966, the CFF launched a quality improvement (QI) initiative in 2002 by "assembling national experts to develop a strategic plan to disseminate QI training and processes" [16]. This registry and the Foundation facilitated the rapid identification of improvement opportunities [16]. From 2002 to 2013, 90\% of all cystic fibrosis centers in the United States (US) participated in 11 QIC projects [17]. The collaborative used the Dartmouth Clinical Microsystem applied theory and curriculum, which focuses on improving small clinical units using various quality improvement methods [66, 67]. Collaborative members communicated frequently through monthly webinars and routine coaching calls [17].

CFF was successful in increasing the percentage of patients seen by a respiratory therapist from $69 \%$ in 2006 to $86.7 \%$ in 2012, increasing the percentage of patients seen by a dietician from $70.2 \%$ in 2003 to $87.5 \%$ in 2012 , increasing the median predicted survival of patients from 31.3 years in 2002 to 41.1 years in 2012, and significantly improving patients' forced expiratory volume in $1 \mathrm{~s}$ values (FEV1) from 2002 to 2012 [17, 18].

In 2005, the Joint Council on Congenital Heart Disease developed the National Pediatric Cardiology Quality Improvement Collaborative (NPC-QIC), which works to improve interstage survival for children with a hypoplastic left heart and to decrease interstage growth failure and hospital readmissions [20, 21••]. The NPC-QIC uses the Breakthrough Series collaborative model; activities include monthly data submission with routine reports, monthly webinars, an active listserv, and semi-annual learning session workshops involving healthcare providers and parents $[21 \bullet \bullet, 64]$. The NPC-QIC worked to improve transparency by sharing aggregate outcome data with the public and member

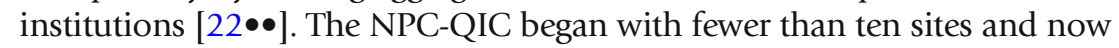
includes more than 50 sites $[21 \bullet \bullet]$.

The NPC-QIC decreased interstage mortality by $44 \%$ from 9.5 to $5.3 \%$, improved growth after implementing a nutritional care bundle, and improved care processes, such as identifying the post-care coordinator and updating the

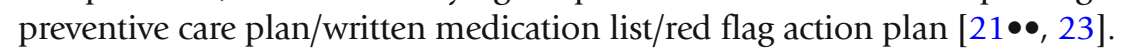
Analysis from a single center found a reduction in interstage mortality correlating to one less patient death per 23 total patients [24]. Annual administrative costs for participating in the collaborative were $\$ 38,271$, and the median revenue provided by caring for a patient for 12 months of life was $\$ 488,944$ [24]. The NPC-QIC also developed a patient data registry that has been used for research purposes $[25 \bullet]$.

ImproveCareNow (ICN) is a pediatric QIC that improves care for children with inflammatory bowel disease [27]. This network originated from the Pediatric Inflammatory Bowel Disease Network Trailblazer Improvement Collaborative formed in 2007 and sponsored by the North American Society for Pediatric Gastroenterology, Hepatology, and Nutrition and the American Board of Pediatrics (ABP) [27]. This network then developed into the ICN Network, with 
more than 100 sites in the US and Europe $[27,28]$. In addition to using the Breakthrough Series collaborative model, ICN uses "theories from leadership of social movements to motivate and build cross-stakeholder collaboration" $[29 \bullet \bullet, 30,64]$. In the planning phase, ICN took input from many stakeholders such as patients, families, pediatric gastroenterologists, nurses, researchers,

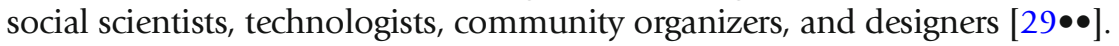
ICN also facilitated data submission by enabling relevant patient data to be sent to the ICN central data repository from participants' electronic health record [31•]. ICN generates data reports for each patient that provide decision support and pre-visit planning [68].

The ICN Collaborative increased the percentage of patients with inactive disease from 55 to $68 \%$ for Crohn's disease and from 61 to $72 \%$ for ulcerative colitis [30]. It also increased the percentage of patients with Crohn's disease not taking prednisone from 86 to $90 \%$ and increased the number of patients in whom complete disease classification and thiopurine methyltransferase genotype was established before initiating a thiopurine medication [30].

The Value in Inpatient Pediatrics (VIP) Network conducted multiple collaborative QI projects for children with bronchiolitis and pneumonia [33-35]. The first bronchiolitis project involved 17 centers from 2007 to 2010, including members volunteering from the American Academy of Pediatrics (AAP) Section on Hospital Medicine [33]. Members adopted national guidelines at their own pace and did not have to follow the guidelines to remain in the collaborative. Most centers performed PDSA cycles. The collaborative generated a yearly report showing each hospital's rates of unnecessary care for bronchiolitis against the network's average. High performers were honored at an annual meeting and encouraged to share successful tools online [33].

The VIP Network conducted a second collaborative targeting bronchiolitis patients from 2013 to 2014 that involved 21 hospitals [34]. The bronchiolitis initiative was sponsored by the Quality Improvement Innovation Network of the AAP [34]. This collaborative was more programmatic, with the implementation of a standardized change package with evidence-based pathways, order sets, and educational materials along with scheduled webinars, a listserv, and individual site coaching [34]. The AAP maintained a website that included performance data and webinar recordings [34].

Running from 2014 to 15 and including 48 hospitals, the VIP Network also worked to improve evidence-based care for patients with pneumonia [35]. Members implemented a standardized change package that included evidencebased pathways and order sets and had regularly scheduled webinars, a project listserv, and individual site coaching [35]. Each site also received a pre-assigned expert to help guide improvement based on their unique needs. The AAP maintained an online workspace for data collection and access to educational materials [35].

The VIP collaboratives demonstrated improvement in multiple areas. The first bronchiolitis collaborative demonstrated a $46 \%$ reduction in the use of bronchodilators and a significant decrease in the use of chest physiotherapy [33]. The second bronchiolitis collaborative demonstrated a $29 \%$ decrease in the number of patients receiving any bronchodilator, a $68 \%$ decrease in the 
amount of corticosteroid use, and a decrease in the length of stay for bronchiolitis patients by $5 \mathrm{~h}$ [34]. The pneumonia collaborative increased the use of narrow-spectrum antibiotics from 36 to $63 \%$ and decreased the use of macrolide antibiotics from 30.3 to $18.6 \%$ [35].

Children's Hospitals' Solutions for Patient Safety (SPS) originated from the Ohio Children's Hospital Association (OCHA), six hospitals that worked together in the 1980s to advocate for pediatric healthcare in Ohio, emerging in 2009 with eight hospitals as Ohio Children's Hospitals' Solutions for Patient Safety (OCHSPS) [37]. Initially, OCHSPS worked to decrease codes outside the ICU, surgical site infections, and adverse drug events through the use of PDSA cycles and data submission to a central registry with real-time data access to facilitate rapid learning across all hospitals [37]. In 2012, OCHSPS expanded to become the nationwide SPS collaborative that initially included 33 children's hospitals [37]. SPS used semi-annual in-person learning sessions, monthly webinars, online discussions, and data submission and to promote an

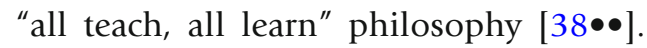

The OCHSPS reduced surgical site infections by $58 \%$ and adverse drug events by $50 \%[37,39]$. Over a 34 -month period, the OCHSPS reduced its serious safety event rate by $55 \%$, which is an estimated 70 fewer children harmed per year [37]. SPS reduced surgical site infections by $21 \%$ from January 2011 to December 2013 and decreased the rate of stage 4 pressure injuries from 0.01 to 0.004 per 1000 patient days $(P=0.02)$ from 2011 to $2013[40 \bullet$, 41 $]$. SPS significantly decreased harm in eight out of nine hospital-acquired conditions and decreased the mean monthly serious safety event rate by $32 \%$ [38••]. As of the latest published results, this work spared an estimated 9000 children

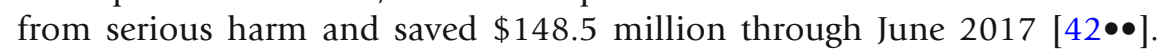
SPS has grown to now include more than 130 member hospitals in the US and Canada. The focus of SPS has expanded to now include numerous additional hospital-acquired harms and employee safety.

Coordinated by the National Institute for Children's Health Quality (NICHQ) using federal funding, the Sickle Cell Disease Treatment Demonstration Program (SCDTDP) ran from 2010 to 2014, with the goal of improving care for patients with sickle cell disease and has another initiative ongoing from 2018 to $2021[47,48]$. This collaborative consisted of nine grantees across the US working to improve various quality measures involving acute care, care coordination, follow-up, and hydroxyurea use. The SCDTDP was modeled after the Breakthrough Series Learning Collaborative [47, 64]. Parents and patients were involved to incorporate the parent and family perspective [47]. NICHQ performed site visits to provide technical assistance to members [47].

The SCDTDP improved the wait time for pain assessment in the acute care setting by $69 \%$ and improved the time between triage and the first dose of pain medication by $29 \%$ [47]. This collaborative improved care coordination with $135 \%$ more patients seen by a hematologist in the previous year [47]. 
The Standardizing Care to Improve Outcomes in Pediatric End Stage Renal Disease (SCOPE) Collaborative reduced the rate of peritoneal dialysis catheterrelated infections by implementing best practices for peritoneal dialysis care [50]. SCOPE was started in 2011 with assistance from quality improvement experts at the Children's Hospital Association (CHA) and by partnering with the North American Pediatric Renal Trials and Collaborative Studies (NAPRTCS) registry [51]. The NAPRTCS registry contains data on patients with pediatric chronic kidney disease from over 100 sites [50]. The NAPRTCS provided Webbased data collection and analysis services for SCOPE [50]. Currently, this collaborative includes 44 sites that implement standardized best-care bundles for catheter insertion, provide training to patients and caregivers for catheter care, and conduct follow-up procedures [50,52]. To encourage group learning, the collaborative has two face-to-face learning sessions per year, monthly webinars/conference calls, one-on-one coaching of members, and monthly data sharing [50]. The individual institutions provide financial support for this collaborative [50].

The SCOPE Collaborative decreased peritonitis from 0.63 per patient year to 0.42 per patient year and found that increasing compliance with standardized follow-up practices was associated with decreased peritonitis [51, 53].

\section{Other pediatric quality improvement collaboratives and data collection groups}

Pediatric Rheumatology Care and Outcomes Improvement Network (PRCOIN) was founded in 2011 to improve outcomes for patients with juvenile idiopathic arthritis and includes 18 member hospitals [54, 55•]. PR-COIN receives funding from the Patient-Centered Outcomes Research Institute, American College of Rheumatology (ACR), participating member hospitals, and pharmaceutical companies $[54,56]$. This collaborative uses the Breakthrough Series collaborative model with monthly webinars, "learning labs," and semi-annual learning sessions, and sites contribute data to a central registry maintained by the ACR [57, 64]. Patients and families are part of this improvement process and help to set priorities, with one parent on the governing body [58].

The PR-COIN Collaborative has increased remission rates from 37.2 to $48.4 \%$ and has seen improvements in various quality measures such as measurement of functional ability and improved uveitis screening [57, 59, 60].

The Childhood Cancer \& Blood Disorders Network (CCBDN) was organized by the CHA in 2009 to reduce central line-associated bloodstream infections (CLABSIs) in pediatric hematology/oncology inpatients [44]. The CCBDN reduced the rate of CLABSIs from 2.85 to 2.04 CLABSIs per 1000 central-line days, thereby preventing an estimated 290 CLABSIs with a likely cost savings of approximately $\$ 11$ million [45]. The Improving Patient Handoffs Quality Improvement Collaborative started in 2010 and was coordinated by the Child Health Corporation of America (CHCA), which then became part of the CHA 


\section{Discussion}

[49]. This collaborative decreased handoff-related failures from 25.8 to $7.9 \%$, and overall satisfaction with the handoff improved from 55 to $70 \%$ [49].

More recently formed collaboratives focus on diagnostic stewardship and sepsis. The Blood Culture Improvement Guidelines and Diagnostic Stewardship for Antibiotic Reduction in Critically Ill Children (Bright STAR Collaborative) was founded by Johns Hopkins Children's Center in January 2018. The Bright STAR Collaborative is implementing a clinical practice strategy for diagnostic stewardship of blood cultures in the critical care setting but has not yet published outcome data [63]. The Improving Pediatric Sepsis Outcomes (IPSO) was created by the CHA in 2015, with the goal of reducing sepsis-related mortality by $75 \%$ and hospital-onset severe sepsis by $75 \%$ by 2020 , but has not yet published outcome data [61,62]. Other collaborative improvement efforts are embedded within federal funding mechanisms. For example, centers funded by the federal Ryan White program, which provides care for a substantial portion of pediatric HIV patients, must participate in the HIVQUAL program which guides care improvement through clinical guidelines, measurement, and improvement methods [69-71].

The National Surgical Quality Improvement Program-Pediatric (NSQIPPediatric) and Pediatric Cardiac Critical Care Consortium (PC4) are two organizations that collect large amounts of data on pediatric patients but do not fully meet the QIC definition used in this review based on their level of focus and organized communication of a QIC outlined in this article [72, 73, 74•, 75•, 76-78]. Several other multi-institutional QI efforts focused on pediatric patients also do not meet the QIC definition outlined in this article: birth certificate data, NICU CLABSI prevention, primary care screening, standardized medication concentrations, handoff improvements, intubation safety, and venous thromboembolism [79-81, 82•, 83•, 84, 85].

We have reviewed features and outcomes of major pediatric QICs, but other impactful QICs have not been covered due to a lack of published data or the authors not being aware of QICs in every pediatric specialty. There are multiple factors that are associated with successful collaboratives. Outlined below are those success-related factors, barriers for success, and potential solutions that can mitigate the challenges associated with conducting a successful collaborative.

Factors leading to the success of pediatric quality improvement collaboratives

\section{Collaborative data sharing and communication}

Free flow of data and communication among members are likely the most important aspects of a successful QIC. SPS used the "all teach, all learn" philosophy to ensure free flow of information among members, with semiannual in-person learning sessions, monthly webinars on various topics, discussions on a password-protected website, and frequent data reporting, so that top-performing hospitals could be identified and share their successful methods with others $[38 \bullet \bullet]$. The NPC-QIC used similar methods $[21 \bullet \bullet]$. The CFF 
went beyond electronic communication and performed benchmarked site visits wherein QI teams visit high-performing sites to see in person what made these sites successful [17].

Data sharing and identifying high-performing hospitals can inspire improvement through public and peer pressure. Public availability of data on the CFF registry may have motivated lower-performing hospitals to improve [16]. In the VIP Network, top performers were honored at a yearly meeting thus potentially creating peer pressure to improve [33].

Data sharing and identifying high-performing hospitals can also motivate improvement work. A hospital working in isolation might accept poor patient safety outcomes because this has always been the accepted norm. However, after joining a QIC and seeing the possibility of better outcomes, it can be motivated to improve. The CFF collaborative reported that data transparency motivated members to learn how to achieve the high-performance measures found at other institutions [17]. We believe a successful QIC can induce a shift in institutional culture and a change from the mindset that some preventable patient harm events are acceptable to the attitude that preventable harm can be reduced or eliminated.

\section{Previous working relationship and trust}

The founding SPS members had already worked with each other for many years as part of the OCHA [37]. The VIP members had previous relationships because they participated in the AAP Section on Hospital Medicine and the AAP Hospital Medicine Listserv [33, 35].

Inter-institutional and interpersonal trust is important for the success of many collaboratives. The sharing of sensitive and parochial data requires the trust that the purpose of the data sharing is to learn from each other, to identify best practices and best outcomes which can be used to drive better patient outcomes. Should such data be used to gain a competitive advantage in the marketplace, the success of learning from each other would likely jeopardize collaborative success. For example, SPS collaborative leadership understood the importance of making sure that sensitive data would be shared without fear of

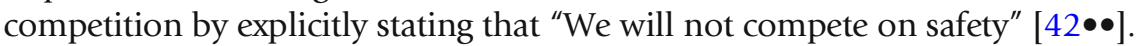

\section{Financial support}

Participating in a QIC can require significant financial resources to pay for clinician time, QI experts, data collection and analysis, and implementing QI changes. Private sources can provide this funding. The OCHSPS received support from the private industry through the Ohio Business Roundtable and from corporations [37]. The PR-COIN received funding from pharmaceutical companies [56].

Some QICs receive funding through member contributions. SPS members pay an annual fee, and PR-COIN receives financial support from its members $[38 \bullet \bullet, 56]$. However, funding the collaborative through member contributions can make it difficult for smaller hospitals to participate.

National organizations and government entities are common sources of funding. The CPQCC received financial support from the California Association of Neonatologists, the David and Lucile Packard Foundation, and the 
California Department of Public Health [9]. The SCDTDP was funded by the NICHQ and the Maternal and Child Health Bureau of the Health Resources and Services Administration [47]. The CCBDN was supported by the Agency for Healthcare Research and Quality and the CHA [45]. PR-COIN received financial support from the ACR [56]. Funding from a national organization allows smaller hospitals with less resources to more easily participate.

Participating in a QIC can be financially beneficial. Analysis from a single center participating in the NPC-QIC found a reduction in interstage mortality correlating to one less patient death per 23 total patients [24]. Annual administrative costs for participating in the collaborative were $\$ 38,271$, and the median revenue provided by caring for a patient for 12 months of life was $\$ 488,944$ [24]. Thus, if this single center has at least 23 hypoplastic left heart patients per year, the hospital will save $\$ 450,673$ compared to not participating in the NPC-QIC. The Michigan Keystone ICU project was also financially beneficial with the average cost of preventing a central line-associated infection at $\$ 3375$ while the healthcare costs associated with a central line-associated infection ranging from $\$ 12,208$ to $\$ 56,167$ [6]. The Children's Hospital Association Quality Transformation Network saved \$129,737,916 through the prevention of central line-associated bloodstream infections from 2006 to 2011 [86]. Hospitals interested in participating in SPS can calculate the financial benefit from participating in the collaborative through the use of a value calculator that incorporates data regarding cost savings from decreasing

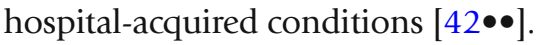

\section{Support from established organizations}

Established organizations provide legitimacy and credibility to a newly formed collaborative, access to patient data, and logistical support for data collection and analysis. Examples include support for ICN by the North American Society for Pediatric Gastroenterology, Hepatology, and Nutrition and the ABP, for the CFF collaborative by the Cystic Fibrosis Foundation, for the VIP Network by the AAP, and for the NPC-QIC by the Joint Council on Congenital Heart Disease $[16,17,21 \bullet \bullet, 27,35]$.

\section{Theoretical framework}

Starting a pediatric QIC can be daunting because it requires extensive logistical coordination. Most successful QICs used an already existing theoretical framework to guide this collaboration. Many pediatric QICs have used some form of the Breakthrough Series collaborative model because it has a proven track record of success $[10,21 \bullet \bullet, 30,47,49,57,64]$. Interestingly, the ICN Network also used "theories from leadership of social movements to motivate and build cross-stakeholder collaboration," which shows the importance of social engineering [29••]. Using an existing, proven theoretical framework to launch a QIC increases the feasibility for smaller institutions without QI expertise to participate.

\section{Patient and family involvement}

Involving patients and families in the collaborative can help identify areas for improvement. Multiple collaboratives have made a conscious effort to involve 
patients and families $[17,21 \bullet \bullet, 29 \bullet \bullet, 47,58]$. The NPC-QIC had trouble getting parents involved but solved this problem by reaching out to Sisters by Heart, a parent organization for families affected by hypoplastic left heart syndrome $[21 \bullet \bullet]$. PR-COIN took parental involvement a step further by appointing a parent on its governing body [58].

\section{Incentives for participation}

Many collaboratives give incentives to individuals and institutions to increase participation. Several collaboratives encouraged individual participation by providing American Board of Pediatrics Maintenance of Certification Part 4 Credit $[21 \bullet \bullet, 34,86]$. The NPC-QIC encouraged institutional support with NPC-QIC participation, resulting in points for the US News and World Report's rankings of best pediatric cardiology programs $[21 \bullet \bullet]$. However, although concrete incentives can increase participation at both the individual and institutional levels, there is the risk of participants becoming overly focused on obtaining these concrete incentives by meeting metrics rather than concentrating on actual improvement.

\section{Barriers to the success of pediatric quality improvement collaboratives}

\section{Insufficient funding or resources as a barrier to participation in network}

Multiple QICs reported that institutions that are small or have less resources had limited participation $[8,30,37]$. ICN reported that some centers had lower levels of improvement, likely reflecting the lack of resources at these centers [30]. This illustrates the limited ability of QICs to help smaller resource-poor institutions. This is unfortunate because these institutions need QI the most to maximize patient outcomes in resource-limited settings. A possible solution is to fund the QICs through various government entities, private organizations, national physician organizations, or national disease-based organizations rather than depending on member contributions $[9,37,45,47,56]$.

\section{Legal concerns regarding sharing patient data}

Legal concerns can arise when sharing sensitive patient safety data, especially when data indicate preventable patient harm are shared across state lines. The NPC-QIC made efforts to make their data sharing more transparent but met with concerns from hospital legal departments $[22 \bullet \bullet]$. Obtaining legal protection for data sharing can prove difficult, especially since hospitals often focus on state protections and QICs include institutions in different states with different state laws and governments. Although the OCHSPS had legal protection for sharing patient data, members raised concerns [37]. The legal protection provided by Ohio's peer review statute applies to SPS data and outcomes through the creation of an SPS Peer Review Committee, and over time legal concerns have not limited growth in SPS. As healthcare safety and quality data become more transparent, these concerns may diminish, but 
additional federal legal protections may facilitate data sharing at a national level.

\section{Consensus on best practices and outcome measures}

In the case of rare pediatric diseases for which many guidelines for clinical management are not available, it can be difficult to reach a consensus on best practices and most important outcome measures. This problem was especially apparent in the NPC-QIC and ICN collaboratives because of their focus on relatively rare diagnoses $[21 \bullet \bullet, 30]$. A potential solution is to involve nationally recognized experts in the field to develop expert consensus opinion for unifying the collaborative $[21 \bullet \bullet, 45,51]$. QICs can also help reach consensus by providing "large, representative study samples with high-quality data that can be used to generate evidence and inform clinical decision-making" [87].

\section{Existing institutional practices, inertia, and culture}

QI efforts involve changing an existing institutional practice. Although a change in practice can be supported by evidence, the institutional culture still needs to be changed to implement this evidence. The VIP Network found that the strongest association with failure to decrease unnecessary bronchiolitis treatments was having a bronchiolitis protocol before joining the network [33]. The CFF collaborative found that some members were initially hesitant to participate because they had trouble believing they were not delivering the best possible care and doubted the accuracy of registry data [16].

The OCHSPS used various task forces to create an error prevention safety culture at both the employee and leadership levels [37]. The CPQCC asked members for direct input on the design of interventions to improve institutional buy in [8].

Members of the collaborative also need to be assured that the culture of the collaborative is one of learning and not shaming or punishing for lower performance. Members of the CFF collaborative initially had concerns about being punished for not performing at optimal levels and had to be reassured that the culture of the collaborative was one of learning [16]. SPS made efforts to make clear that the culture of the collaborative is not one of competition but of focus on patient safety by stating that "We will not compete on safety" and utilizing the "all teach, all learn" philosophy $[38 \bullet \bullet, 42 \bullet \bullet]$.

\section{Conclusion}

The diversity and scale of QICs in pediatrics is impressive. We observed commonalities in the improvement methods used as well as barriers and success factors reported. As the number of QICs continues to grow, and the rapid cycle improvement approach evolves toward long-term continuous improvement efforts, competition for scarce resources will necessitate continued innovation to optimize efficiency and sustainability. For example, opportunities may exist to combine efforts across QICs or share common data management infrastructure. It will be important for collaboratives to share not only outcomes but 
also details of how successes are achieved in the literature to foster further growth and maturation of the QIC approach.

\section{Compliance with Ethical Standards}

\section{Conflict of Interest}

Richard J. Brilli declares no conflict of interest.

Michael Terao reports the National Institutes of Health grant CA 21765 and the American Society of Pediatric Hematology/Oncology 2019 Clinician Educator Award (http://aspho.org/career-development/awards/clinicianeducator-award).

James M. Hoffman is supported by ALSAC and the National Institutes of Health grants CA 21765 and R24GM115264.

Amanda Finch receives a salary from Solutions for Patient Safety (SPS). Some of the SPS funding is provided under a contract funded by CMS for a Hospital Improvement Innovation Network. Amanda Finch is a Communications Specialist with the Anderson Center at Cincinnati Children's, a hub which supports several of the QICs discussed in this paper.

Kathleen E. Walsh receives a salary from Solutions for Patient Safety (SPS). Some of the SPS funding is provided under a contract funded by CMS for a Hospital Improvement Innovation Network. Dr. Walsh is a research leader with the Anderson Center, a hub which supports several of the QICs discussed in this paper.

Maitreya Coffey receives a salary from Solutions for Patient Safety (SPS). Some of the SPS funding is provided under a contract funded by CMS for a Hospital Improvement Innovation Network.

Human and Animal Rights and Informed Consent

This article does not contain any studies with human or animal subjects performed by any of the authors.

\section{References and Recommended Reading}

Papers of particular interest, published recently, have been highlighted as:

- Of importance

- Of major importance

1. Institute of Medicine, Committee on Quality of Health Care in America. To Err Is Human: Building a Safer Health System [Internet], National Academies Press; 2000. Available from: https://www.ncbi.nlm.nih.gov/ books/NBK225182/

2. Institute of Medicine: Committee on Quality of Health Care in America. Crossing the Quality Chasm: A New Health System for the 21st Century [Internet]. In: Briere R, editor. Washington, DC: National Academies Press; 2001. Available from: https://www.ncbi.nlm.nih.gov/ books/NBK222274/pdf/Bookshelf_NBK222274.pdf

3. Stockwell DC, Landrigan CP, Toomey SL, Loren SS, Jang J, Quinn JA, et al. for the GAPPS Study Group Adverse events in hospitalized pediatric patients. Pediatrics [Internet]. Am Acad Pediatr. 2018;142. https:// doi.org/10.1542/peds.2017-3360.
4. Cabana MD, Rand CS, Powe NR, Wu AW, Wilson MH, Abboud PA, et al. Why don't physicians follow clinical practice guidelines? A framework for improvement. JAMA [internet]. 1999;282:1458-65. Available from: https://www.ncbi.nlm.nih.gov/pubmed/10535437.

5.• Wells S, Tamir O, Gray J, Naidoo D, Bekhit M, Goldmann D. Are quality improvement collaboratives effective? A systematic review. BMJ Qual Saf [Internet]. 2018;27:226-40. https://doi.org/10.1136/bmjqs2017-006926.

This is a systematic review and meta-analysis of the effectiveness of quality improvement collaboratives. This article also provides a comprehensive and clear definition of a quality improvement collaborative.

6. Waters HR, Korn R Jr, Colantuoni E, Berenholtz SM, Goeschel CA, Needham DM, et al. The business case for quality: economic analysis of the Michigan Keystone 
Patient Safety Program in ICUs. Am J Med Qual [Internet]. 2011;26:333-9. https://doi.org/10.1177/ 1062860611410685.

7. Pronovost P, Needham D, Berenholtz S, Sinopoli D, Chu $\mathrm{H}$, Cosgrove S, et al. An intervention to decrease catheter-related bloodstream infections in the ICU. N Engl J Med [Internet]. 2006;355:2725-32. https://doi. org/10.1056/NEJMoa061115.

8. Bennett SC, Finer N, Halamek LP, Mickas N, Bennett $\mathrm{MV}$, Nisbet CC, et al. Implementing delivery room checklists and communication standards in a multineonatal ICU quality improvement collaborative. Jt Comm J Qual patient Saf [internet]. 2016;42:369-76. Available from: https://www.ncbi.nlm.nih.gov/ pubmed/27456419.

9. California Perinatal Quality. Who We Are [Internet]. California Perinatal Quality Care Collaborative. [cited 2018 Oct 9]. Available from: https://www.cpqcc.org/ about/who-we-are

10.• Lee HC, Bennett MV, Crockett M, Crowe R, Gwiazdowski SG, Keller H, et al. Comparison of collaborative versus single-site quality improvement to reduce NICU length of stay. Pediatr Int. 2018;142:e20171395. https://doi.org/10.1542/peds.2017-1395.

This study from the California Perinatal Quality of Care Collaborative demonstrates greater improvement in quality improvement collaboratives compared to individual institutions working in isolation. However, it is important to keep in mind that there could have been significant selection bias regarding which institutions joined the collaborative effort making this data less reliable.

11. Lee HC, Kurtin PS, Wight NE, Chance K, CucinottaFobes T, Hanson-Timpson TA, et al. A quality improvement project to increase breast milk use in very low birth weight infants. Pediatr Int. 2012;130:e167987. https://doi.org/10.1542/peds.2012-0547.

12. Lapcharoensap W, Bennett MV, Powers RJ, Finer NN, Halamek LP, Gould JB, et al. Effects of delivery room quality improvement on premature infant outcomes. J Perinatol [Internet]. 2017;37:349-54. https://doi.org/ 10.1038/jp.2016.237.

13. Lee HC, Powers RJ, Bennett MV, Finer NN, Halamek LP, Nisbet C, et al. Implementation methods for delivery room management: a quality improvement comparison study. Pediatr Int. 2014;134:e1378-86. https://doi.org/10.1542/peds.2014-0863.

14. Walsh MC, Crowley M, Wexelblatt S, Ford S, Kuhnell P, Kaplan HC, et al. Ohio Perinatal Quality Collaborative improves care of neonatal narcotic abstinence syndrome. Pediatrics [internet]. 2018;141. https://doi. org/10.1542/peds.2017-0900.

This article describes a successful collaborative effort by the CPQCC to decrease total treatment time and length of stay for neonatal abstinence syndrome.

15. California Perinatal Quality Care Collaborative | [Internet]. [cited 2018 Nov 5]. Available from: https:// www.cpqcc.org/

16. Mogayzel PJ Jr, Dunitz J, Marrow LC, Hazle LA. Improving chronic care delivery and outcomes: the impact of the cystic fibrosis Care Center Network. BMJ Qual Saf [Internet]. 2014;23(Suppl 1):i3-8. https:// doi.org/10.1136/bmjqs-2013-002363.

17. Godfrey MM, Oliver BJ. Accelerating the rate of improvement in cystic fibrosis care: contributions and insights of the learning and leadership collaborative. BMJ Qual Saf [Internet]. 2014;23(Suppl 1):i23-32. https://doi.org/10.1136/bmjqs-2014-002804.

18. Marshall BC, Nelson EC. Accelerating implementation of biomedical research advances: critical elements of a successful 10 year Cystic Fibrosis Foundation healthcare delivery improvement initiative. BMJ Qual Saf [Internet]. 2014;23(Suppl 1):i95-103. https://doi.org/ 10.1136/bmjqs-2013-002790.

19. Godfrey M. Email from Majorie Godfrey to Michael Terao. 2018.

20. Kugler JD, Iii BRH, Rosenthal GL, Jenkins KJ, Klitzner TS, Martin GR, et al. Development of a pediatric cardiology quality improvement collaborative: from inception to implementation. From the Joint Council on Congenital Heart Disease Quality Improvement Task Force. Congenit Heart Dis [Internet]. 2009;4:318-28. https://doi.org/10.1111/j.1747-0803.2009.00328.x.

21.• Anderson JB, Beekman RH 3rd, Kugler JD, Rosenthal GL, Jenkins KJ, Klitzner TS, et al. Improvement in interstage survival in a national pediatric cardiology learning network. Circ Cardiovasc Qual Outcomes [Internet]. 2015;8:428-36. https://doi.org/10.1161/ CIRCOUTCOMES.115.001956.

This paper summarizes the efforts and success of the National Pediatric Cardiology Quality Improvement Collaborative to improve survival in infants with hypoplastic left heart. It describes many of the challenges faced by this collaborative and the ways these challenges were overcome.

22.• Lihn SL, Kugler JD, Peterson LE. Transparency in a pediatric quality improvement collaborative: a passionate journey by NPC-QIC clinicians and parents. Congenit Heart Dis [Internet]. Wiley Online Library; 2015;10:572-80. Available from: https://onlinelibrary. wiley.com/doi/abs/10.1111/chd.12314.

This paper describes the barriers faced by the National Pediatric Cardiology Quality Improvement Collaborative as it attempted to make data sharing more transparent among member institutions and the public.

23. Anderson JB, Beekman RH III, Kugler JD. Use of a learning network to improve variation in interstage weight gain after the Norwood operation. Congenit Heart Dis [internet]. Wiley Online Library; 2014;9:512-20. Available from: https://onlinelibrary. wiley.com/doi/abs/10.1111/chd.12232

24. Anderson JB, Brown D, Lihn S, Tweddell J, Hansen J, McDonald M, et al. Revenue return on investment for center involvement in a quality improvement collaborative for a rare disease: national pediatric cardiology quality improvement collaborative. J Am Coll Cardiol [Internet]. 2017;69:612 Available from:http://www. onlinejacc.org/content/69/11_Supplement/612.

25. Hill GD, Rudd NA, Ghanayem NS, Hehir DA, Bartz PJ. Center variability in timing of stage 2 palliation and 
association with interstage mortality: a report from the National Pediatric Cardiology Quality Improvement Collaborative. Pediatr Cardiol [Internet].

2016;37:1516-24. https://doi.org/10.1007/s00246016-1465-9.

This is a report from the National Pediatric Cardiology Quality Improvement Collaborative that demonstrates how a QIC can be used for research purposes in addition to quality improvement purposes.

26. National Pediatric Cardiology Quality Improvement Collaborative [Internet]. [cited 2018 Nov 5]. Available from: https://npcqic.org/

27. Crandall W, Kappelman MD, Colletti RB, Leibowitz I, Grunow JE, Ali S, et al. ImproveCareNow: the development of a pediatric inflammatory bowel disease improvement network. Inflamm Bowel Dis [Internet]. 2011;17:450-7. https://doi.org/10.1002/ibd.21394.

28. ImproveCareNow. Care centers [Internet]. ImproveCareNow. [cited 2018 Oct 9]. Available from: https:// www.improvecarenow.org/care-centers

29.• Seid M, Dellal G, Peterson LE, Provost L, Gloor PA, Fore DL, et al. Co-designing a Collaborative Chronic Care Network (C3N) for inflammatory bowel disease: development of methods. JMIR Hum Factors [Internet]. 2018;5:e8. https://doi.org/10.2196/

humanfactors.8083.

This article describes the intricate process used to design the ImproveCareNow Network, including using ideas from social movements to increase collaboration and buy in.

30. Crandall WV, Margolis PA, Kappelman MD, King EC, Pratt JM, Boyle BM, et al. Improved outcomes in a quality improvement collaborative for pediatric inflammatory bowel disease. Pediatr Int.

2012;129:e1030-41. https://doi.org/10.1542/peds. 2011-1700.

31. Marsolo K, Margolis PA, Forrest CB, Colletti RB, Hutton JJ. A digital architecture for a network-based learning health system: integrating chronic care management, quality improvement, and research. EGEMS (wash DC) [internet]. 2015;3:1168. https://doi.org/10. 13063/2327-9214.1168.

This article describes how collaboration with electronic medical record vendors helped ImproveCareNow design software that significantly reduced the data entry burden faced by clinicians.

32. ImproveCareNow. ImproveCareNow [Internet]. ImproveCareNow. [cited 2018 Nov 5]. Available from: https://www.improvecarenow.org/

33. Ralston S, Garber M, Narang S, Shen M, Pate B, Pope J, et al. Decreasing unnecessary utilization in acute bronchiolitis care: results from the value in inpatient pediatrics network. J Hosp Med [Internet]. 2013;8:2530. https://doi.org/10.1002/jhm.1982.

34. Ralston SL, Garber MD, Rice-Conboy E, Mussman GM, Shadman KA, Walley SC, et al. A multicenter collaborative to reduce unnecessary care in inpatient bronchiolitis. Pediatr Int. 2016;137:eds. 2015-0851. https://doi.org/10.1542/peds.2015-0851.
35. Parikh K, Biondi E, Nazif J, Wasif F, Williams DJ, Nichols E, et al. A multicenter collaborative to improve care of community acquired pneumonia in hospitalized children. Pediatr Int. 2017;139:e20161411. https://doi.org/10.1542/peds.2016-1411.

36. Ralston S. Email from Shawn Ralston to Maitreya Coffey. 2018.

37. Lyren A, Brilli R, Bird M, Lashutka N, Muething S. Ohio children's hospitals' solutions for patient safety: a framework for pediatric patient safety improvement. J Healthc Qual [Internet]. 2013;38(4):213-22. Available from: https://onlinelibrary.wiley.com/doi/pdf/10. 1111/jhq.12058.

38.• Lyren A, Brilli RJ, Zieker K, Marino M, Muething S, Sharek PJ. Children's hospitals' solutions for patient safety collaborative impact on hospital-acquired harm. Pediatr Int. 2017; 140:e20163494 Available from: http://pediatrics.aappublications.org/content/140/3/ e20163494

This paper highlights the success of the Children's Hospitals' Solutions for Patient Safety Network in reducing hospitalacquired harm in multiple areas. This article is a strong example of the power of the "all teach, all learn" philosophy to drive rapid improvement.

39. Toltzis $\mathrm{P}, \mathrm{O}^{\prime}$ Riordan M, Cunningham DJ, Ryckman FC, Bracke TM, Olivea J, et al. A statewide collaborative to reduce pediatric surgical site infections. Pediatr Int. 2014;134:e1174-80. https://doi.org/10.1542/peds. 2014-0097.

40. $\quad$ Frank G, Walsh KE, Wooton S, Bost J, Dong W, Keller $\mathrm{L}$, et al. Impact of a pressure injury prevention bundle in the solutions for patient safety network. Pediatr Qual Saf [Internet]. 2017;2:e013. Available from: https://www.ncbi.nlm.nih.gov/pmc/articles/ PMC6132915/.

This paper describes the success of the Children's Hospitals' Solutions for Patient Safety Network in reducing pressure injuries through implementation of a pressure injury prevention bundle. This network functioned through the "all teach, all learn" philosophy with the sharing of keys to success and common barriers encountered during this implementation to accelerate improvement.

41.• Schaffzin JK, Harte L, Marquette S, Zieker K, Wooton S, Walsh $\mathrm{K}$, et al. Surgical site infection reduction by the solutions for patient safety hospital engagement network. Pediatr Int. 2015;136:e1353-60. https://doi.org/ 10.1542/peds.2015-0580.

This article highlights the success of the Children's Hospitals' Solutions for Patient Safety Network in reducing surgical site infections through a quality improvement collaborative. This network used the "all teach, all learn" philosophy to share keys to success and common barriers in the implementation of the prevention bundle.

42.• Lyren A, Coffey M, Shepherd M, Lashutka N, Muething S, SPS Leadership Group. We will not compete on safety: how children's hospitals have come together to hasten harm reduction. Jt Comm J Qual patient Saf [internet]. Elsevier; 2018;44:377-88. https://doi.org/ 10.1016/j.jcjq.2018.04.005. 
This article is a summary of the successful efforts of the Children's Hospitals' Solutions for Patient Safety Network to decrease preventable harm to children and employees/staff.

43. Children's Hospitals' Solutions for Patient Safety [Internet]. [cited 2018 Nov 5]. Available from: https:// www.solutionsforpatientsafety.org/

44. Gaur AH, Bundy DG, Werner EJ, Hord JD, Miller MR, Tang L, et al. A prospective, holistic, multicenter approach to tracking and understanding bloodstream infections in pediatric hematology-oncology patients. Infect Control Hosp Epidemiol [Internet]. 2017;38:690-6. https://doi.org/10.1017/ice.2017.57.

45. Bundy DG, Gaur AH, Billett AL, He B, Colantuoni EA, Miller MR, et al. Preventing CLABSIs among pediatric hematology/oncology inpatients: national collaborative results. Pediatr Int. 2014;134:e1678-85. https:// doi.org/10.1542/peds.2014-0582.

46. Esporas M. Email from Megan Esporas to Michael Terao. 2018.

47. National Institute for Children's Health Quality. Sickle Cell Disease Treatment Demonstration Program: Congressional Report [Internet]. 2014. Available from: http://med.stanford.edu/content/dam/sm/cpop/ documents/Wang-NICHQ_SCDTDP-CongressionalReport-Oct-2014.pdf. Accessed 7 Nov 2018.

48. Sickle Cell Disease Treatment Demonstration Regional Collaborative Program National Coordinating Center [Internet]. NICHQ - National Institute for Children's Health Quality. [cited 2018 Nov 7]. Available from: https://www.nichq.org/project/sickle-cell-diseasetreatment-demonstration-regional-collaborativeprogram-national.

49. Bigham MT, Logsdon TR, Manicone PE, Landrigan CP, Hayes LW, Randall KH, Grover P, Collins SB, Ramirez DE, O'Guin CD, Williams CI, Warnick RJ, Sharek PJ Decreasing handoff-related care failures in children's hospitals. Pediatrics [internet]. Am Acad Pediatrics; 2014;134:e572-9. Available from: doi:https://doi.org/ 10.1542/peds.2013-1844

50. Neu AM, Miller MR, Stuart J, Lawlor J, Richardson T, Martz K, et al. Design of the standardizing care to improve outcomes in pediatric end stage renal disease collaborative. Pediatr Nephrol [Internet].

2014;29:1477-84. https://doi.org/10.1007/s00467014-2891-7.

51. Neu AM, Richardson T, Lawlor J, Stuart J, Newland J, McAfee $\mathrm{N}$, et al. Implementation of standardized follow-up care significantly reduces peritonitis in children on chronic peritoneal dialysis. Kidney Int [Internet]. Elsevier; 2016 [cited 2018 26];89:1346-54. Available from: doi:https://doi.org/10.1016/j.kint. 2016.02.015

52. Children's Hospital Association. SCOPE Dialysis Collaborative [Internet]. Children's Hospital Association. [cited 2018 Oct 10]. Available from: https://www. childrenshospitals.org/Programs-and-Services/ Quality-Improvement-and-Measurement/ Collaboratives/SCOPE
53. Sethna CB, Bryant K, Munshi R, Warady BA, Richardson T, Lawlor J, et al. Risk factors for and outcomes of catheter-associated peritonitis in children: the SCOPE collaborative. Clin J Am Soc Nephrol [Internet]. 2016;11:1590-6. https://doi.org/10.2215/CJN. 02540316.

54. PR-COIN. Teams [Internet]. PR-COIN. [cited 2018 Oct 10]. Available from: https://pr-coin.org/pr-cointeams

55. Harris JG, Bingham CA, Morgan EM. Improving care delivery and outcomes in pediatric rheumatic diseases. Curr Opin Rheumatol [internet]. 2016;28:110-6. https://doi.org/10.1097/BOR.0000000000000257.

The authors summarize the structure and successes of the Pediatric Rheumatology Care and Outcomes Improvement Network.

56. PR-COIN. About [Internet]. PR-COIN. [cited 2018 Oct 10]. Available from: https://pr-coin.org/about

57. DeWitt EM, Ardoin SP, Bingham C, Gottlieb BS, Laxer $\mathrm{RM}$, Griffin N, et al. Increasing rates of remission in juvenile idiopathic arthritis through a quality improvement learning network-the Pediatric Rheumatology Care and Outcomes Improvement Network [internet]. 2014. Available from: https://acrabstracts.org/ abstract/increasing-rates-of-remission-in-juvenileidiopathic-arthritis-through-a-quality-improvementlearning-network-the-pediatric-rheumatology-careand-outcomes-improvement-network/

58. DeWitt EM, Fricke K, Bergheger L, Griffin N, Laxer RM, Jones KB, et al. A147: engaging patients and families in the pediatric rheumatology care and outcomes improvement network. Arthritis Rheum [Internet]. 2014;66:S190-0. http://doi.wiley.com/10.1002/art. 38568.

59. Harris JG, DeWitt EM, Laxer RM, Ardoin SP, Gottlieb BS, Olson JC, et al. A151: pediatric rheumatology care and outcomes improvement network demonstrates performance improvement on juvenile idiopathic arthritis quality measures. Arthritis Rheum [Internet]. 2014;66:S195-5. http://doi.wiley.com/10.1002/art. 38577.

60. Oliver MS, Weiss JE, Li SC, Haines KA, Janow GL, Dewitt EM, et al. Enhancing uveitis screening compliance in juvenile idiopathic arthritis patients: 2789. Arthritis Rheum [Internet] Arthritis \& Rheumatism. 2013;65:S1193-4. Available from: https://insights. ovid.com/arthritis-rheumatism/arhe/2013/10/001/ enhancing-uveitis-screening-compliance-juvenile/ 2789/00000889.

61. Children's Hospital Association. Improving pediatric sepsis outcomes: a multi-year collaborative for children's hospitals to reduce sepsis mortality and morbidity across all levels of care [Internet]. Available from: https:// www.childrenshospitals.org/-/media/Files/CHA/Main/ Programs_and_Services/Quality_Safety_and_ Performance/Collaboratives/Sepsis/Prospectus_CHA_ Sepsis_Collaborative.la=en\&hash= D27A7AE9893E1373B3194E507CAC0CEA5811CA28. Accessed 22 Oct 2018. 
62. Children's Hospital Association. Improving pediatric sepsis outcomes - March 2015 newsletter [Internet]. Children's Hospital Association. 2015 [cited 2018 Oct 26]. Available from: https://www. childrenshospitals.org/newsroom/newsletters/ improving-pediatric-sepsis-outcomes/2015/ improving-pediatric-sepsis-outcomes-march-2015

63. Bright STAR Collaborative | Johns Hopkins Children's Center [Internet]. Johns Hopkins Children's Center. [cited 2018 Oct 22]. Available from: https://www. hopkinsmedicine.org/johns-hopkins-childrens-center/ what-we-treat/specialties/infectious-diseases/ programs-centers/bright-star/index.html

64. Kilo CM. A framework for collaborative improvement lessons from the Institute for Healthcare Improvement's Breakthrough Series. Qual Manag Health Care [Internet]. 1998;6:1-13. Available from: http://www. centertrt.org/content/docs/Intervention_Documents/ Intervention_Materials/OSNAP/Framework_for_ Collaborative.

65. Britto MT, Fuller SC, Kaplan HC, Kotagal U, Lannon C, Margolis PA, et al. Using a network organisational architecture to support the development of Learning Healthcare Systems. BMJ Qual Saf [Internet]. 2018;27:937-46. https://doi.org/10.1136/bmjqs2017-007219.

66. Nelson EC, Batalden PB, Huber TP, Mohr JJ, Godfrey MM, Headrick LA, et al. Microsystems in health care: part 1. Learning from high-performing front-line clinical units. Jt Comm J Qual Improv [internet]. Elsevier; 2002;28:472-93. Available from: https://www.ncbi. nlm.nih.gov/pubmed/12216343.

67. Nelson EC, Batalden PB, Godfrey MM. Quality by design: a clinical microsystems approach: John Wiley \& Sons; 2011.

68. Forrest CB, Margolis P, Seid M, Colletti RB. PEDSnet: how a prototype pediatric learning health system is being expanded into a national network. Health Aff [Internet]. 2014;33:1171-7. https://doi.org/10.1377/ hlthaff.2014.0127.

69. Quality Improvement [Internet]. New York State Department of Health AIDS Institute. [cited 2018 Nov 7]. Available from: https://www.hivguidelines.org/ quality-of-care/about-the-program/qualityimprovement/

70. New York State Department of Health AIDS Institute Health Resources and Services Administration HIV/ AIDS Bureau. HIVQUAL Workbook [Internet]. New York State Department of Health AIDS Institute Health Resources and Services Administration HIV/AIDS Bureau ; 2006. Available from: http:// nationalqualitycenter.org/files/hivqual-workbook/

71. Weiser J, Beer L, Frazier EL, Patel R, Dempsey A, Hauck $\mathrm{H}$, et al. Service delivery and patient outcomes in Ryan White HIV/AIDS Program-funded and-nonfunded health care facilities in the United States. JAMA Intern Med [internet]. American Medical Association; 2015;175:1650-9. Available from: https:// jamanetwork.com/journals/jamainternalmedicine/ fullarticle/2430794

72. Brighton BK. National Surgical Quality Improvement Program-Pediatric (NSQIP) and the quality of surgical care in pediatric orthopaedics. J Pediatr Orthop [Internet]. 2015;35:S48-50. https://doi.org/10.1097/BPO. 0000000000000548.

73. Bruny JL, Hall BL, Barnhart DC, Billmire DF, Dias MS, Dillon PW, et al. American College of Surgeons National Surgical Quality Improvement Program Pediatric: a beta phase report. J Pediatr Surg [Internet]. 2013;48:74-80. https://doi.org/10.1016/j.jpedsurg. 2012.10.019.

74. Serres SK, Cameron DB, Glass CC, Graham DA, Zurakowski D, Karki M, et al. Time to appendectomy and risk of complicated appendicitis and adverse outcomes in children. JAMA Pediatr [Internet]. 2017;171:740-6. https://doi.org/10.1001/jamapediatrics.2017. 0885jamanetwork.com.

This article summarizes outcome data regarding appendicitis from the NSQIP-Pediatric, which does not meet the definition of a quality improvement collaborative outlined in this article but is a large pediatric data-gathering group.

75. $\quad$ Basques BA, Lukasiewicz AM, Samuel AM, Webb ML, Bohl DD, Smith BG, et al. Which pediatric orthopaedic procedures have the greatest risk of adverse outcomes? J Pediatr Orthop [Internet]. 2017;37:429-34. https:// doi.org/10.1097/BPO.

0000000000000683 ingentaconnect.com.

This is a report from the National Surgical Quality Improvement Program-Pediatric that looks at adverse outcomes for pediatric orthopedic procedures. While the National Surgical Quality Improvement Program-Pediatric does not meet the definition of a quality improvement collaborative outlined in this article it is visible in aggregating data for definition of a quality improvement collaborative outlined in this article it is visible in aggregating data for pediatrics surgery.

76. Gaies M, Cooper DS, Tabbutt S, Schwartz SM, Ghanayem N, Chanani NK, et al. Collaborative quality improvement in the cardiac intensive care unit: development of the Paediatric Cardiac Critical Care Consortium (PC4). Cardiol Young [Internet]. 2015;25:951-7. https://doi.org/10.1017/ S1047951114001450.

77. Alten JA, Klugman D, Raymond TT, Cooper DS, Donohue JE, Zhang W, et al. Epidemiology and outcomes of cardiac arrest in pediatric cardiac ICUs. Pediatr Crit Care Med [Internet]. 2017;18:935-43. https://doi.org/10.1097/PCC.0000000000001273.

78. Gaies MG, Jeffries HE, Niebler RA, Pasquali SK, Donohue JE, Yu S, et al. Vasoactive-Inotropic Score (VIS) is associated with outcome after infant cardiac surgery: an analysis from the Pediatric Cardiac Critical Care Consortium (PC4) and virtual PICU system registries. Pediatr Crit Care Med [Internet]. 2014;15:-529. Available from: https://www.ncbi.nlm.nih.gov/pmc/ articles/PMC4159673.

79. Warren BB, Ranade D, Wathen B, Valdez S, Pickard D, Goldenberg NA, et al. Daily evaluation of venous 
thromboembolism (vte) risk factors and prophylaxis safely decreased incidence of VTE in a pediatric ICU. Blood [Internet]. American Society of Hematology; 2014 [cited 2018 26];124:4860-4860. Available from: http://www.bloodjournal.org/content/124/21/4860. abstract

80. Iams J, Ford S, White B, Bouchard J, Friar K, Kassouf M, et al. 766: Dissemination of an obstetrical quality improvement (QI) initiative using birth certificates. Am J Obstet Gynecol [internet]. Elsevier; 2013;208:S321-2. Available from: doi:https://doi.org/10.1016/j.ajog. 2012.10.104.

81. Shein D, Bowen J, Callander I, Richards R, Bowers S, Lindrea $\mathrm{KB}$, et al. A state-wide collaborative quality improvement programme: decreasing central line associated blood stream infections. J Paediatr Child Health [Internet]. 2013;49:103. Available from: https://insights.ovid.com/paediatrics-child-health/ jpechh/2013/04/000/state-wide-collaborative-qualityimprovement/327/00002208.

82. Meropol SB, Schiltz NK, Sattar A, Stange KC, Nevar $\mathrm{AH}$, Davey C, et al. Practice-tailored facilitation to improve pediatric preventive care delivery: a randomized trial. Pediatr Int. 2014;133:e1664-75. https://doi.org/ 10.1542/peds.2013-1578.

This study looked at the effectiveness of a practice facilitator visiting various primary care clinics to improve preventive care. The use of a practice facilitator to help clinics with their preventative care delivery resulted in significant improvement in preventive care delivery. This article describes a method to improve primary care services in a somewhat collaborative setting.

83.• Engels MJ, Ciarkowski SL, Rood J, Wang B, Wagenknecht LD, Dickinson CJ, et al. Standardization of compounded oral liquids for pediatric patients in
Michigan. Am J Health Syst Pharm [Internet].

2016;73:981-90. https://doi.org/10.2146/150471.

This study involved multiple pharmacies in Michigan with a statewide effort to standardize medication concentrations to decrease errors. While this statewide effort does not meet the definition of a QIC outlined in this article, this was one of the few efforts to focus explicitly on the quality of the medication use process.

84. Starmer AJ, Spector ND, Srivastava R, West DC, Rosenbluth $G$, Allen $A D$, et al. Changes in medical errors after implementation of a handoff program. $\mathrm{N}$ Engl J Med [Internet]. 2014;371:1803-12. https://doi.org/10. 1056/NEJMsa1405556.

85. Nishisaki A, Lee A, Li S, Sanders R, Brown C, Napolitano N, et al. 1072: Multicenter qi collaborative to improve safety of pediatric icu tracheal intubations. Crit Care Med [Internet]. 2016;44:344. https://doi.org/ 10.1097/01.ccm.0000509748.23142.24.

86. Billett AL, Colletti RB, Mandel KE, Miller M, Muething SE, Sharek PJ, et al. Exemplar pediatric collaborative improvement networks: achieving results. Pediatr Int. 2013;131(Suppl 4):S196-203. https://doi.org/10. 1542/peds.2012-3786F.

87. Clancy CM, Margolis PA, Miller M. Collaborative networks for both improvement and research. Pediatr Int. 2013;131(Suppl 4):S210-4. https://doi.org/10.1542/ peds.2012-3786H.

\section{Publisher's Note}

Springer Nature remains neutral with regard to jurisdictional claims in published maps and institutional affiliations. 